\title{
Approach for a Pattern-Based Development of Frugal Innovations
}

\section{Anne-Christin Lehner, Christian Koldewey, and Jürgen Gausemeier}

\author{
"Creativity and insight almost always involve an") \\ experience of acute pattern recognition: the eureka \\ moment in which we perceive the interconnection \\ between disparate concepts or ideas to reveal \\ something new.
}

Jason Silva

Futurist, filmmaker, and public speaker

\begin{abstract}
Emerging markets have become increasingly interesting for companies from industrialized countries, but the requirements in these markets differ dramatically from those in the companies' traditional markets. New products and services are demanded - so-called frugal innovations. Since the challenges for the development of frugal innovations are often quite similar - for example, low income of the target customer, poor infrastructure, etc. - the hypothesis appears that the solutions will also be similar. In our earlier TIM Review article (Lehner \& Gausemeier, 2016), we showed how solution patterns for frugal innovations can be derived. The article at hand summarizes those findings and supplements an innovation process for frugal innovation using the solution patterns. The validation based on the example of telemedical assistant systems shows the benefit of the pattern-based development of frugal innovations. The article addresses managers and engineers who plan to introduce frugal innovations, as well as university-based researchers interested in the development of frugal innovations.
\end{abstract}

\section{Introduction}

In 1980 , almost $80 \%$ of global gross goods turnover was generated in industrialized countries. Since then, this share has been steadily declining; by 2013 , almost $40 \%$ of gross goods turnover had already been converted to developing and emerging countries (McKinsey Global Institute, 2015). In recent years, markets in developing and emerging countries have thus increasingly become the focus of international companies (Högl \& Weiss, 2014). However, customers in these markets are much more price-sensitive and demand products and services that are adapted to their local needs. One of the most common names for such products and services is the term frugal innovations (Basu et al., 2013; The Economist, 2010), but see Box 1 for a list of related terms. Besides the redesigning of products, the adaptation of the entire value chain and of the business model is equally important for frugal innovations (The Economist, 2010). We define frugal innovations in accordance with Eagar and colleagues (2011), Tiwari and Herstatt (2014), and Lehner (2016):

Frugal innovations are novel or significantly modified market products and services and business models adapted to the needs of the poorer populations in developing and emerging countries.

Frugal innovations usually focus on the price (Bound \& Thornton, 2012; Tiwari \& Herstatt, 2014; Zeschky et al., 2011), but also on sustainability and social aspects (Bhatti, 2012; Bound \& Thornton, 2012). An example of a sustainable frugal innovation is a water filter with a replaceable filter cartridge, developed by the University of Aalto for Ahlstrom. In Tanzania, it removes the need to boil drinking water, which usually consumes firewood or charcoal. In doing so, greenhouse gases are reduced and deforestation and adverse health effects are avoided (Hyvärinen et al., 2016). In practice, there are many other examples of frugal innovations. 


\section{Approach for a Pattern-Based Development of Frugal Innovations}

\section{Anne-Christin Lehner, Christian Koldewey, and Jürgen Gausemeier}

The target group for these products and services is, in most cases, the global middle class; they have experienced a significant increase in prosperity over the past few years. According to the World Bank, the global middle class includes people who have between $\$ 2$ and $\$ 13$ USD a day at their disposal (Ravallion, 2009). Large sections of the population are still lacking money for expensive products from the highly developed industrialized countries (Tiwari \& Herstatt, 2013; Zeschky et al., 2011). In addition, the products must also meet requirements different from industrialized countries today (Gausemeier \& Wiendahl, 2011), as they are used in a completely different environment. With such products, western companies can maintain their competitive position against upcoming competitors from emerging markets (e.g., Haier or Huawei) (Radjou et al., 2012).

However, many western companies are not exploiting the existing potential for frugal innovations. For example, in a survey of more than 60 companies, Roland Berger Strategy Consultants found out that only $29 \%$ of the companies surveyed are satisfied with frugal innovations' profits (Roland Berger Strategy Consultants, 2013). Reasons for this low level of satisfaction include time problems with the planning of product costs and the design of the value chain; a lack of market knowledge or competitive prices; and shortages of local engineering and problem-solving skills (Roland Berger Strategy Consultants, 2015). Overall, existing R\&D and innovation processes in western companies are often optimized for the development of advanced products and technologies. Most of the time, the resulting products are still based on a western product architecture and therefore are not suitable as frugal innovations (Zeschky et al., 2011). However, the innovation process of frugal innovations is hardly considered in the literature. Often, the focus is on the actual product or service (Hossain, 2016). This prevents both the conceptual and managerial understanding and exploitation of the potentials of frugal innovations (Hossain et al., 2017), therefore leaving a research gap for the development of a frugal innovation process.

The pattern-based solution of recurring problems in the course of the development of a technical system has proven itself in many domains; this applies, for example, to the operating principles of mechanical design and to the design pattern of software development. According to Alexander and co-authors (1995), a pattern encompasses "a problem that occurs repeatedly in our environment, the core of the solution to this problem, in such a way that this solution can be used millions of times without ever repeating itself". Several patterns in
Box 1. Terms related to "frugal innovation"

In addition to the term frugal innovation, the literature contains a large number of other terms dealing with innovations in the context of developing and emerging countries. These include:

- resource-constrained innovation

(Capasso et al., 2013; Ray \& Ray 2010)

- cost innovation

(Williamson, 2010)

- reverse innovation

(Govindarajan \& Trimble, 2012)

- frugal re-engineering

(Shivaraman et al., 2012)

- shanzhai

(Kao \& Lee, 2010)

- lean innovation

(Tiwari \& Herstatt, 2012)

- disruptive innovation

(Bower \& Christensen, 1995; Tiwari \& Herstatt, 2012)

- jugaad

(Radjou et al., 2012)

- grassroots innovation

(Hilmi, 2012; Seyfang \& Smith, 2007)

- inclusive innovation

(Heeks et al. 2013; Nijhof et al., 2002)

- bottom of the pyramid innovation

(Bieger \& Reinhold, 2011; Ernst et al., 2013)

- Ghandian innovation

(Prahalad \& Mashelkar 2010)

a domain can be grouped together to form so-called pattern catalogues. If the dependencies between the patterns are also considered, the implementation described, and the problem-solving process supported, it is considered a pattern system (Buschmann et al., 2000). It is therefore clear that, with the aid of patterns, solutions can be externalized, structured, and documented; complexity and input are reduced and a uni- 


\section{Approach for a Pattern-Based Development of Frugal Innovations}

\section{Anne-Christin Lehner, Christian Koldewey, and Jürgen Gausemeier}

form communication is created (Amshoff et al., 2014). In this way, expert knowledge can be transferred to non-experts (Corfman, 1998), for example, expert knowledge about problems and solutions in frugal markets can be used by engineers in industrialized countries. An indication for the benefits of a pattern-based approach for frugal innovation is provided by Tiwari \& Herstatt (2013): the analysis of three case studies shows that developers are very specifically looking for analogies in the development of frugal innovations, which are strongly focused on cost reduction and efficiency. The search is not limited to the early innovation phase, but extends over the entire innovation process.

Therefore, we believe that the transmission of the solution pattern approach to the development of frugal innovations is very promising to address the problems mentioned above. To prove this point, the three following hypotheses have to be validated (Lehner et al., 2015):

1. Product developers face similar problems while developing market services and business models for developing and newly industrializing countries (e.g., insufficient infrastructure, adverse climatic conditions, etc.).

2. If the problems are similar, the solutions will also be similar as well.

3. By abstracting the applied solutions to patterns, they can be used to develop market services and business models facing similar problems.

To validate the first and second hypotheses, we derived a frugal innovation pattern system analyzing 29 frugal innovations from different countries and industries. This is shown in the next section; a more detailed description of the pattern system can be found in our 2016 TIM Review article (Lehner \& Gausemeier, 2016). The third hypothesis is validated in the section after that. We used the design research methodology (Blessing \& Charkrabarti, 2009) to derive the innovation process model for pattern-based frugal innovation presented there. The last section summarizes the findings and gives a conclusion.

\section{Solution Patterns for Frugal Innovation}

The frugal innovation pattern system is developed in a four-step procedure (Lehner, 2016; Lehner \& Gausemeier, 2015; Lehner et al., 2015) and is based upon the design pattern theory (e.g., Alexander et al., 1995; Buschmann et al., 2000; Zimmer, 1995). The procedure is explained below:

1. First of all, a representative overview of existing frugal innovations has to be compiled, which is documented in the form of frugal innovation profiles. This is necessary because the inductive approach to finding patterns is the agreed paradigm in the pattern community. The inductive approach is based upon the observation and analysis of existing cases (Kohls \& Wedekind, 2011).

2. Given that a solution pattern addresses a recurring problem (Alexander et al., 1995), the causal problems are identified that prevented the use of a product and a business model from an industrialized country and led to the development of the frugal innovations. The identified problems can be clustered into six problem areas: environment, infrastructure, education, culture, regulation, and finance. In addition, it is possible to identify which aspects of the product and business model are affected by the problems.

3. The second component of a solution pattern is the core of the solution to the recurring problem (Alexander et al., 1995). Therefore, it is determined how the researched frugal innovations coped with the identified problems. These solutions are abstracted to extract the core idea of the solution in such a way that it is transferable to other problems. Figure 1 shows this procedure using electrocardiography (ECG) devices. The analysis of the device for industrialized countries revealed, for example, that its use in remote areas in developing and emerging countries is not possible due to the lack of resistance of the installed print heads to temperature and humidity. This problem can be assigned to the problem area environment and the impact area solution element. The problem is solved by the device for developing and emerging countries by using printers from bus stations in India. Abstraction results in the Pattern "Use of existing technologies from other industries".

4. An analysis of the pattern catalogue can be used to obtain further information, for example, how widespread a pattern is or with which patterns it frequently occurs together. Such information supports the author and user of the solution pattern: it helps in choosing the right pattern for a specific situation and closing the gap between patterns as well as understanding the relations between patterns (Buschmann 


\section{Approach for a Pattern-Based Development of Frugal Innovations}

\section{Anne-Christin Lehner, Christian Koldewey, and Jürgen Gausemeier}

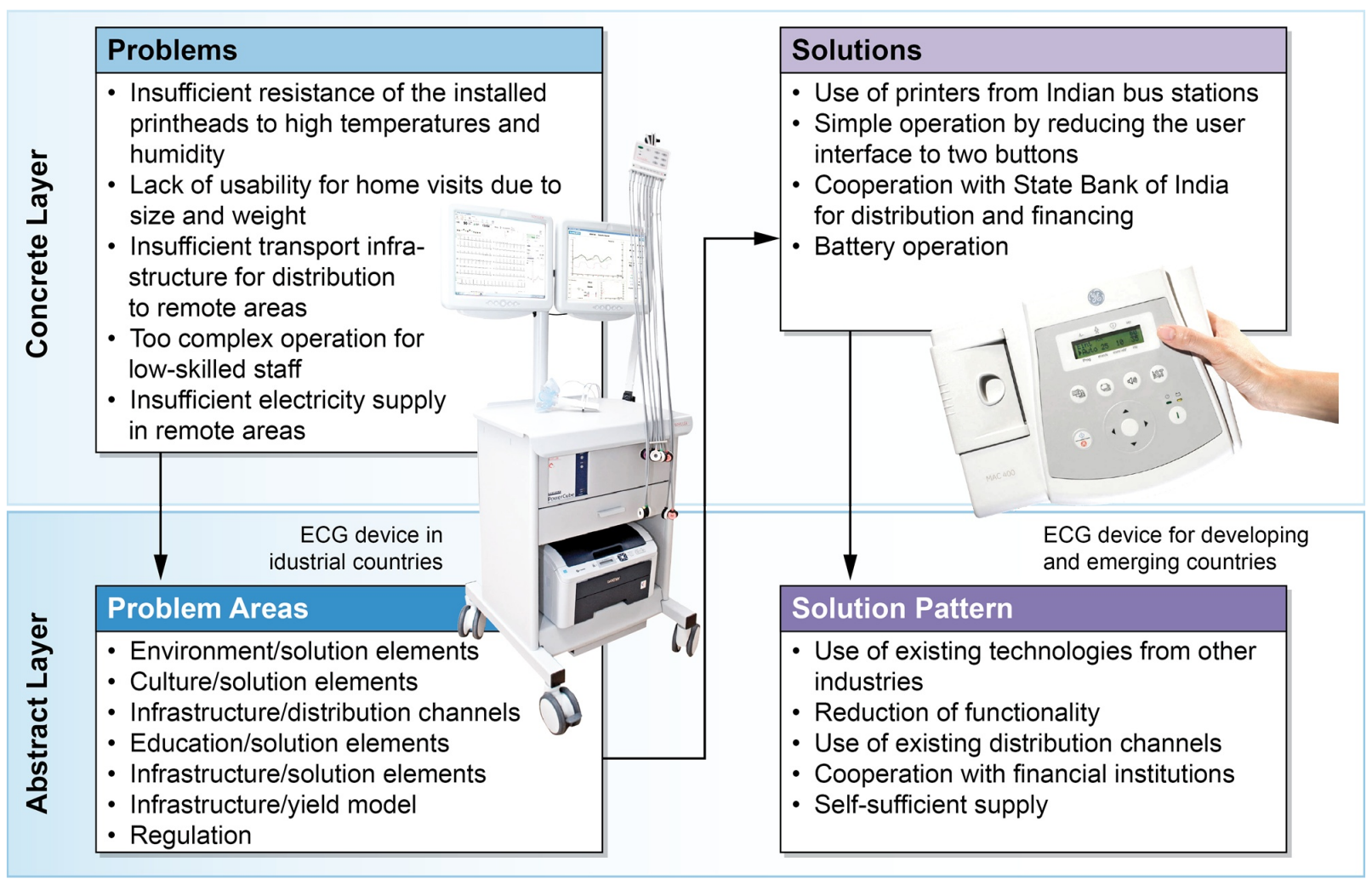

Figure 1. Procedure for the determination of patterns using the example of ECG devices (Lehner, 2016)

et al., 2000). The patterns are finally documented as pattern profiles. A profile includes a description, best practices, and classification in the pattern system. Figure 2 shows an overview of the identified solution patterns for the problem area "infrastructure".

\section{Process Model for Pattern-Based Frugal Innovation}

We, therefore, propose a four-stage process model for the development of frugal innovations in accordance with Figure 3. The starting point of the approach is a given product and business model concept, which is to be adapted for a developing or emerging market (Lehner, 2016). To derive the process model, we used the design research methodology (DRM) (Blessing \& Charkrabarti, 2009). The research was based on a research project classified as DRM type 5. A type 5 research project consists of four elements: clarification of the research objective (goals), descriptive study I (understanding), prescriptive study (solution), and de- scriptive study II (initial evaluation). The article at hand focuses on the results of the prescriptive study. The resulting approach is an innovation process model that integrates common elements of innovation such as an analysis of the environment as well as specific elements for frugal innovation. Such is the focus on the most common problem areas of frugal innovation (environment, infrastructure, education, culture, regulation, and finance) and the application of solution patterns to tackle specific problems in those problem areas.

The four elements of the proposed process model can be summarized as follows:

1. Identification of target markets: First of all, the approximately 150 developing and emerging countries potentially eligible for a frugal innovation will be successively narrowed down. The selection of promising target markets is based on the dimensions of market attractiveness and fit to the boundary conditions. 


\section{Approach for a Pattern-Based Development of Frugal Innovations} Anne-Christin Lehner, Christian Koldewey, and Jürgen Gausemeier

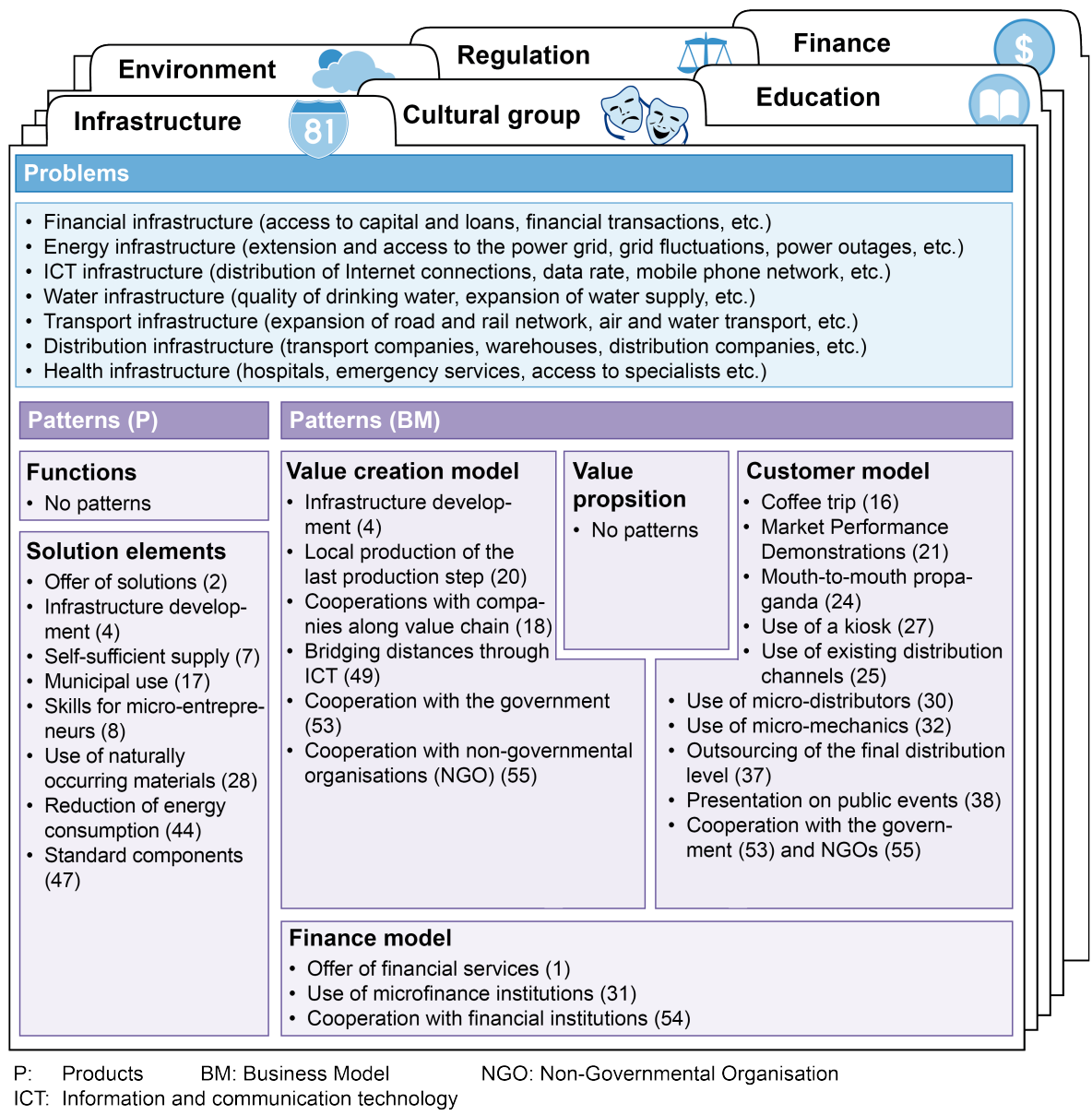

Figure 2. Overview of the identified solution patterns for the problem area "infrastructure" (Lehner, 2016)

Phases/Milestones

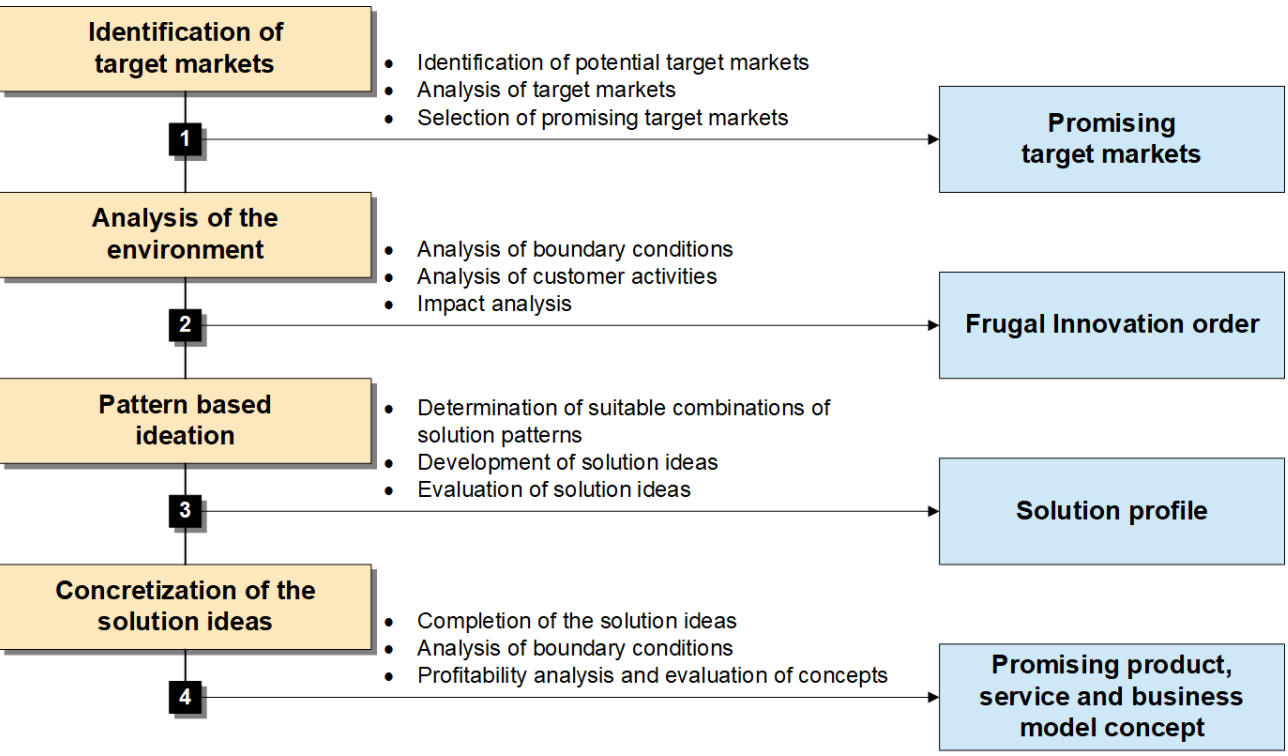

Figure 3. Process model for the pattern-based development of frugal innovations (Lehner, 2016) 


\section{Approach for a Pattern-Based Development of Frugal Innovations}

\section{Anne-Christin Lehner, Christian Koldewey, and Jürgen Gausemeier}

2. Analysis of the environment: The objective is to identify problems in the transfer of products and business models to developing or emerging countries. To this end, the boundary conditions and customer needs, as well as comparable market services, are analyzed. The findings result in a frugal innovation development order.

3. Pattern-based ideation: The objective is to find solutions for the identified problems. For this purpose, patterns are used and creativity workshops are held. The ideas are put together in a morphological environment, they are evaluated, and then the most promising ones are selected.

4. Concretization of the ideas: Finally, the ideas for market service and business model concepts are concretized, while taking account of economic considerations. The final concept is selected on the basis of the dimensions of cost-effectiveness, fit to the boundary conditions, and customer needs. On the basis of the concept, initial feasibility studies can then be carried out.

In the following section, the explained procedure is illustrated. The starting point for the system is a product and a market service for industrialized countries that are to be offered in fresh markets.

\section{Approach in Detail}

Here, we illustrate the explained procedure using the example of a telemedical assistance system for monitoring the health status of patients.

\section{Identification of target markets}

The identification of suitable target markets is carried out in several steps. According to the definition of frugal innovation, all developing and emerging countries are the starting point - it concerns about 150 countries. First of all, a restriction can be made on the basis of macroeconomic criteria. A geographical limitation (e.g., only Latin America and the Caribbean) is carried out and the number of inhabitants is evaluated. The size of the sales market is of paramount importance due to the low-profit margin attainable with frugal innovations (Universe Foundation, 2013). A further refinement of the relevant target markets makes it possible to examine macroeconomic location factors, for example, with the help of the Economic Freedom Index (The Heritage Foundation, 2015). The final selection of the target markets is based on microeconomic criteria. Three assessment dimensions are taken into account: market attractiveness, fit to the conditions, and fit to the company.

- Market attractiveness: It results from the consideration of the criteria market potential, competitive intensity, expected benefit, and future relevance.

- Fit to the boundary conditions: In doing so, six problem areas identified in the analysis of more than 30 frugal innovations are taken into account as criteria. The problem areas are environment, infrastructure, education, culture, regulation, and finance.

- Fit to the company: The starting position of the company is considered here. The criteria of local presence, market knowledge, and strategy conformity are used.

The selection of the target market for frugal innovation is then made on the basis of a bubble chart shown in Figure 4. In this example, Egypt was selected as the target market.

\section{Analysis of the environment}

The objective of this phase is the frugal innovation order. This includes a description of possible problems of the product and the business model for the introduction in the target market. The identification of the problems is based on an analysis of the current and future boundary conditions as well as customer needs in the target market. Based upon that, the environmental effects on the western product and the business model are finally determined.

- Analysis of the boundary conditions: This is carried out in two steps. First, so-called descriptive factors are determined. They characterize the differences between the source and target markets. The six problem areas of frugal innovations form the framework for the analysis. An example of a descriptive factor from the problem area of infrastructure is information and communication technology. Second, the descriptive factors are characterized by means of indicators. An indicator for the descriptive factor mentioned above is, for example, fixed broadband access per inhabitant. The characteristics of the indicators are then determined in the initial and target market. In Germany, for example, $95 \%$ of the population has a broadband connection; in Egypt only 3\% does. In addition, the future development of the indicator in the target market is assessed.

- Identification of customer needs: This is conducted in three steps. First, substitutes are identified for the 


\section{Approach for a Pattern-Based Development of Frugal Innovations}

\section{Anne-Christin Lehner, Christian Koldewey, and Jürgen Gausemeier}

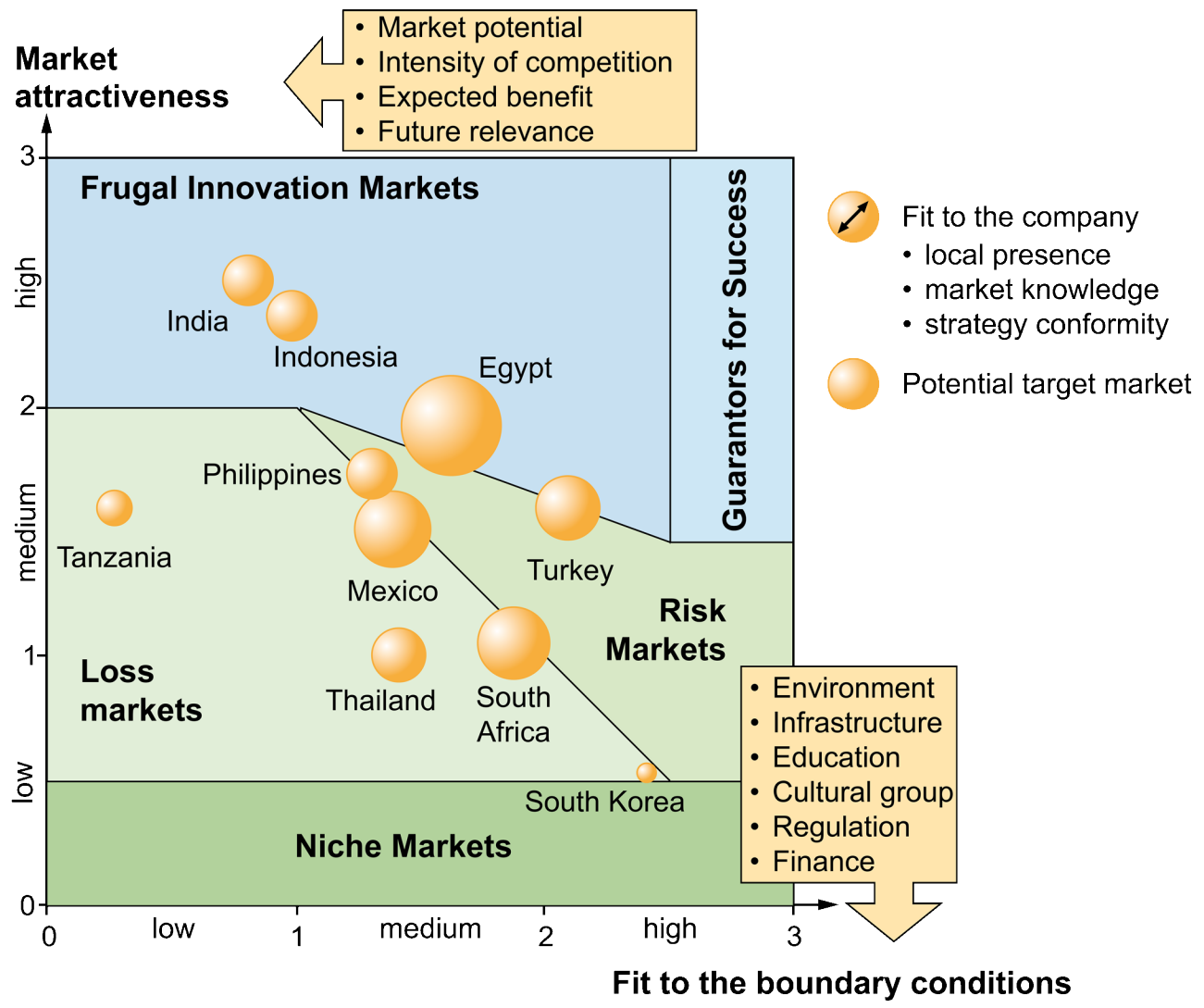

Figure 4. Bubble chart for selecting suitable target markets (Lehner, 2016)

targeted product in the target market. Second, customers are then observed when using substitutes. Customer activities are recorded in the form of a process description. Third, the documentation of the results summarizes customer needs that are addressed with the individual substitutes and evaluates their fulfillment by the substitutes. The findings are recorded in profiles.

- Determination and assessment of the effects: Two steps are carried out. First, based on the boundary conditions and local needs, the effects on the current business model and the product offered are determined. In order to assess the effects, the boundary conditions and customer needs of the product are compared with the business model (Figure 5). Depending on the application, different views must be taken into account. Figure 5 (right) shows a selection of possible views of the object of observation. The problems are derived from the views on the object of observation. For example, the analysis of the product can be carried out on the basis of its functionality, shape, or solution elements. The identified problems are then assigned to the problem areas and the areas of impact. Areas of impact characterize which elements of the product (func- tions or elements) and of the business model (e.g., customer segments) are affected by the problem. Second, the analysis of the environment thus shows the need for action for a frugal innovation. As shown in Figure 6 , the results are summarized in a frugal innovation order. It contains a description and evaluation of the current product and the current business model as well as an overview of the identified problems. The problems are summarized in the problem matrix. The matrix contains the problem areas in the rows and the elements of the business model and products in the columns. The cells indicate whether an element of the business model or product is affected by problems from a problem area. The customer needs profile also assesses how well the current concept meets customer requirements.

\section{Pattern-based brainstorming}

Ideas are developed to solve the identified problems. Given that frugal innovations often face recurring problems, such as poor infrastructure, adverse climatic conditions, or lack of education, a pattern-based approach to find solutions is recommended. For this purpose, solution patterns are used, which have been identified by the analysis of existing frugal innovations. Ideas are 


\section{Approach for a Pattern-Based Development of Frugal Innovations}

\section{Anne-Christin Lehner, Christian Koldewey, and Jürgen Gausemeier}
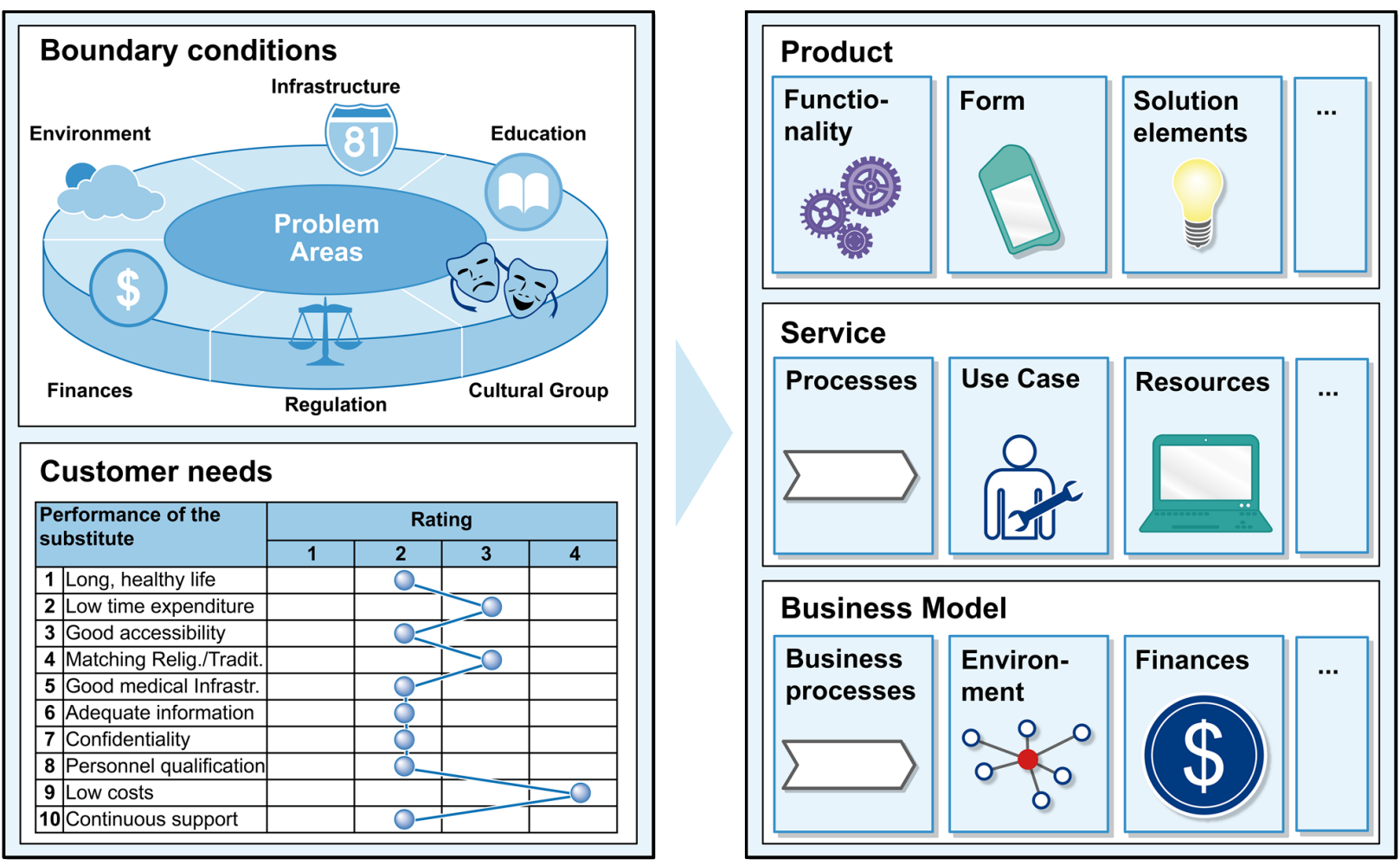

Figure 5. Comparison of boundary conditions and customer needs with the product (including services) and the business model (Lehner, 2016)

generated cyclically and successively improved with each pass through as the requirements of the target market are approached. A cycle always consists of three steps: the identification of suitable combinations of patterns, the development of ideas, and the evaluation of ideas. At the end of each cycle, a decision is made whether the cycle has to be run again, whether the idea has to be postponed, or whether the idea is passed on to concretization.

- Identification of suitable combinations of patterns: These are patterns that address at least one identified problem area. To solve all existing problems, combinations of patterns are created to cover all problem areas as far as possible. On the one hand, the compatibility of the patterns, and on the other hand, the accuracy of fit, are checked and ensured. The accuracy of fit describes how well the patterns address the problem areas of the application case. The selection of the further pattern combinations is based on the criteria of accuracy of fit, problem-solving potential, and cost-reduction potential. An algorithm then determines from the available combinations of patterns those that are particularly promising.
- Development of ideas: The following process is run for each combination of patterns: First, specific partial ideas are sought for the individual patterns. For problem areas for which there are no patterns, it is necessary to find "conventional" ideas for partial solutions. In both cases, common creativity techniques can be applied. The partial solutions can then be combined in a modified morphological box to form ideas, whereby the lines represent the partial ideas for the individual patterns. For example, the "partial ideas" for the "contact established by the Egyptian Diabetes Association" or "joint information campaigns" can be generated for the "cooperation with NGOs" pattern.

- Evaluation of the ideas: In order to transfer the ideas into the phase of concretization, they have to fulfil three criteria: conformity with the corporate strategy, fit to the boundary conditions, and fulfilment of customer requirements. If this is not the case, it is to decide whether to postpone the idea or run through the cycle again. 


\section{Approach for a Pattern-Based Development of Frugal Innovations} Anne-Christin Lehner, Christian Koldewey, and Jürgen Gausemeier

\begin{tabular}{l}
\hline $\begin{array}{l}\text { Frugal Innovation Order: } \\
\text { Development of a telemedical assistance system for Egypt }\end{array}$ \\
\hline $\begin{array}{l}\text { Market Performance and Business Model } \\
\text { The telemedical assistance system under considerati- } \\
\text { on is used for the therapy of diabetes and hypertensi- } \\
\text { on patients. Using the device, patients can record data } \\
\text { and send it to a database via smartphone. The } \\
\text { attending physician and a medical call centre have } \\
\text { access to these services. Depending on the parame- } \\
\text { ters collected, the patient receives feedback and } \\
\text { recommendations for his or her personal state of } \\
\text { health. The costs for the terminal device and the } \\
\text { service are borne by the patient. They are sold directly } \\
\text { or through pharmacies. }\end{array}$ \\
Editor: A.L.
\end{tabular}

\begin{tabular}{|l|}
\hline Overview of Identified Problems (Excerpt) \\
\hline Environment \\
\hline - EN.1 Fogged screen \\
- EN.2 Vulnerable flap \\
- EN.3 Sensor overheating \\
- EN.4 Poor handling
\end{tabular}

Education

- ED.1 Training of rural doctors

- ED.2 Expert knowledge with the sales partners

- ED.3 Illiteracy of the population

- ED.4 Lack of basic medical knowledge

\begin{tabular}{l}
\hline Regulation \\
- R.1 Authorized representative \\
- R.2 Customer service in the country \\
- R.3 Drug price maintenance
\end{tabular}

\section{Customer Needs}

- CN.1 Insufficient involvement in religion/tradition

- CN.2 Too expensive for citizens of the lower and middle class

\begin{tabular}{|c|c|c|c|c|c|c|c|c|c|c|c|c|c|c|c|c|}
\hline \multicolumn{17}{|c|}{ Evaluation of the existing market performance and business model concept } \\
\hline \multicolumn{12}{|c|}{ Problem matrix } & Customer needs profile & \multicolumn{4}{|c|}{ Rating } \\
\hline & * & *is & $\frac{*}{*}$ & 苗 & ${ }_{4}^{*}$ & $\frac{*}{0}$ & $\frac{1}{*}$ & * & ${ }^{*}$ & $\stackrel{*}{*}$ & $\begin{array}{lll}* \\
*\end{array}$ & Customer needs & 0 & 1 & 2 & 3 \\
\hline & 0 & 0 & 0 & $>$ & $\underline{1}$ & $\underline{x}$ & $\underline{x}$ & & & & & Long, healthy life & & & & 0 \\
\hline 20 & 0 & 0 & 0 & 0 & 0 & 0 & 0 & 0 & 0 & 0 & $x$ & Low time expenditure & & & & Q \\
\hline$(\overline{81})$ & 0 & $x$ & $x$ & 0 & 0 & 0 & 0 & 0 & & & & Good accessibility & & & & -0 \\
\hline (01) & 0 & $\hat{\lambda}$ & $\lambda$ & 0 & 0 & 0 & 0 & 0 & 0 & 0 & $x$ & Matching with religion/tradition & 6 & & & \\
\hline (6) & 0 & 0 & $x$ & $x$ & 0 & 0 & 0 & 0 & 0 & $x$ & $x$ & Good medical infrastructure & & & -0 & \\
\hline$\theta 2$ & 0 & 0 & $x$ & $X$ & 0 & 0 & 0 & 0 & 0 & $x$ & 0 & Adequate information on disease & & & 0 & \\
\hline & & & & & & & & & & & & Good relationship of trust & & & O. & \\
\hline$\Delta \underline{\Delta}$ & 0 & 0 & 0 & 0 & 0 & 0 & 0 & 0 & 0 & 0 & 0 & High qualification of personnel & & & & $=0$ \\
\hline (\$) & & & & & & $x$ & & & & & & \begin{tabular}{|l} 
Low costs \\
Continuous support
\end{tabular} & & & & -O \\
\hline
\end{tabular}

* Elements of the business model (from left to right): customer segments, customer relationships, channels, value proposition, key activities, key resources, key partners, revenue model, cost model

** Elements of market performance (from left to right): functions, solution elements

Figure 6. Profile of a frugal innovation order (Lehner, 2016) 


\section{Approach for a Pattern-Based Development of Frugal Innovations} Anne-Christin Lehner, Christian Koldewey, and Jürgen Gausemeier

For documentation purposes, a profile is created for each idea. After each time a cycle is run, it is updated. The profile contains a concise description of the idea, information on the patterns used, and the number of cycles to be run. It also describes how to solve the identified problems. In addition, the evaluation of the idea with regard to the fit to the boundary conditions and the fit to the customers' needs is presented. Finally, the recommended course of action is listed. Figure 7 shows the solution outline for the idea "Mobile Telemedicine Bus", which will be examined further below.

Solution Idea Profile No. 1.2.1.1 "Mobile Telemedicine Bus".

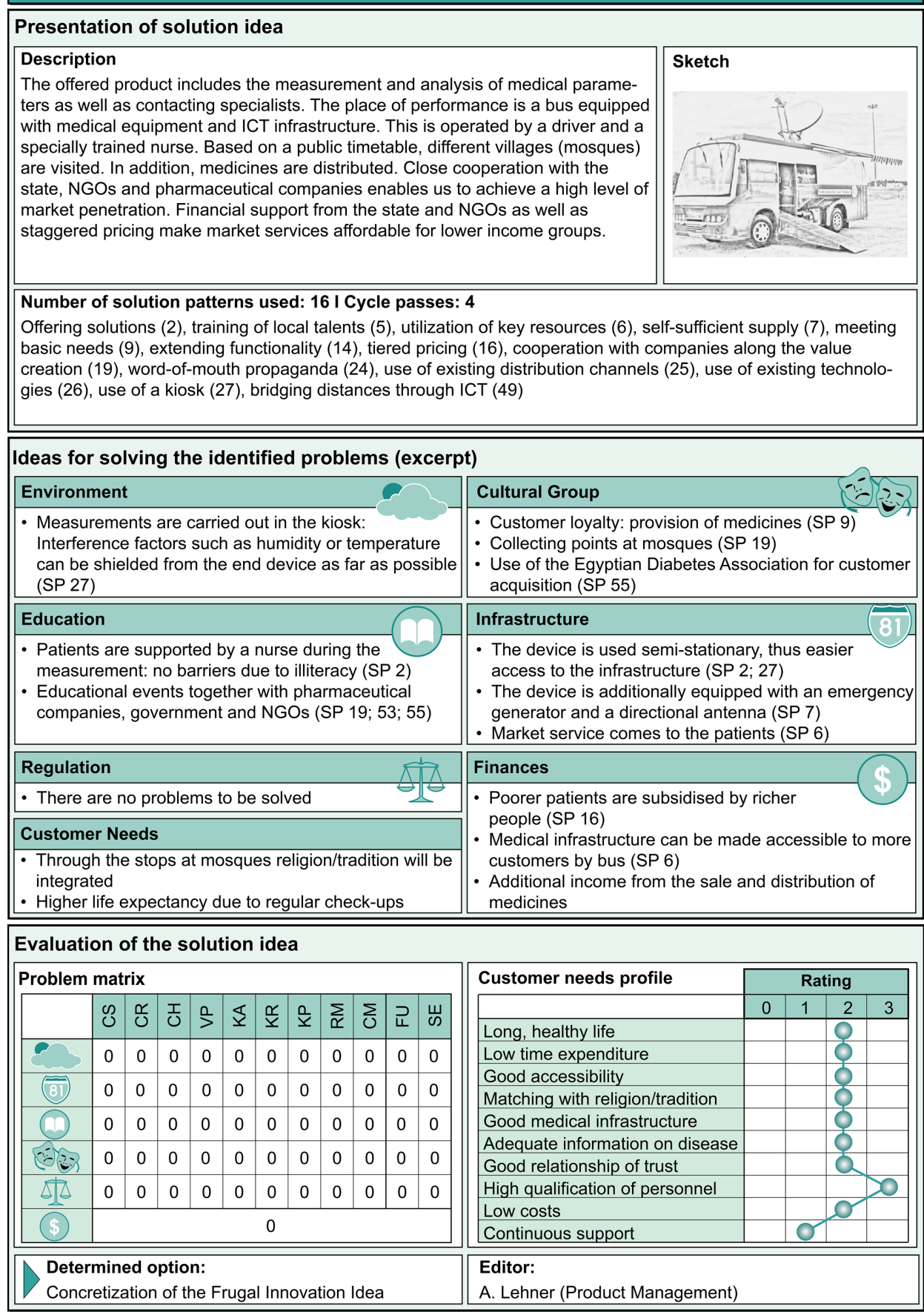

Figure 7. Solution Idea Profile for the idea "Mobile Telemedicine Bus” (Lehner, 2016) 


\section{Approach for a Pattern-Based Development of Frugal Innovations}

\section{Anne-Christin Lehner, Christian Koldewey, and Jürgen Gausemeier}

\section{Concretization of the frugal innovation ideas}

The objective of the last phase is a sustainable product concept and business model concept. To this end, the ideas for solutions handed over to this phase are completed at first. On the basis of the profile, a function and process hierarchy and a business model canvas can be filled initially. The profile for the Mobile Telemedicine Bus, for example, states that problems with the energy and information infrastructure are to be solved by an emergency power generator and a satellite antenna. This results in the functional hierarchy of the functions "Provide energy" and "Receive signals" as well as the corresponding solution elements "Emergency power generator" and "Directional antenna". Different aspects of the business model can also be derived from the idea. For customer acquisition, for example, the network of the Egypt Diabetes Foundation will be used, resulting in its classification as a key partner in the business model. As a rule, there are no comprehensive product and business model concepts available at this point, so it is necessary to refine the existing concept further. For this purpose, the usual methods of product and business model development are used.
Before the final selection of a concept, it is necessary to check whether the assumptions from the analysis of the environment have changed as a result of the concept. In addition, the analyses carried out there will be adapted and expanded. If new challenges arise, the respective solution concept must be adapted accordingly. In our example, three solution concepts achieved this maturity: the "Telemedicine Bus", a "Communal Internet Workstation with Telemedicine Interface", and a "Function-integrated Telemedicine Smartphone". The final selection of a solution concept is based on a bubble chart with the three dimensions fit to the environment, fit to the company and economic efficiency (Figure 8). These are explained below.

- Fit to the environment: It is checked whether the idea solves the identified problems (fit to the boundary conditions). In addition, it is determined whether the customer needs are met (fit to the customer needs).

- Fit to the company: An important criterion is the corporate strategy (fit to the corporate strategy). In addition, it is examined whether the idea can be realized

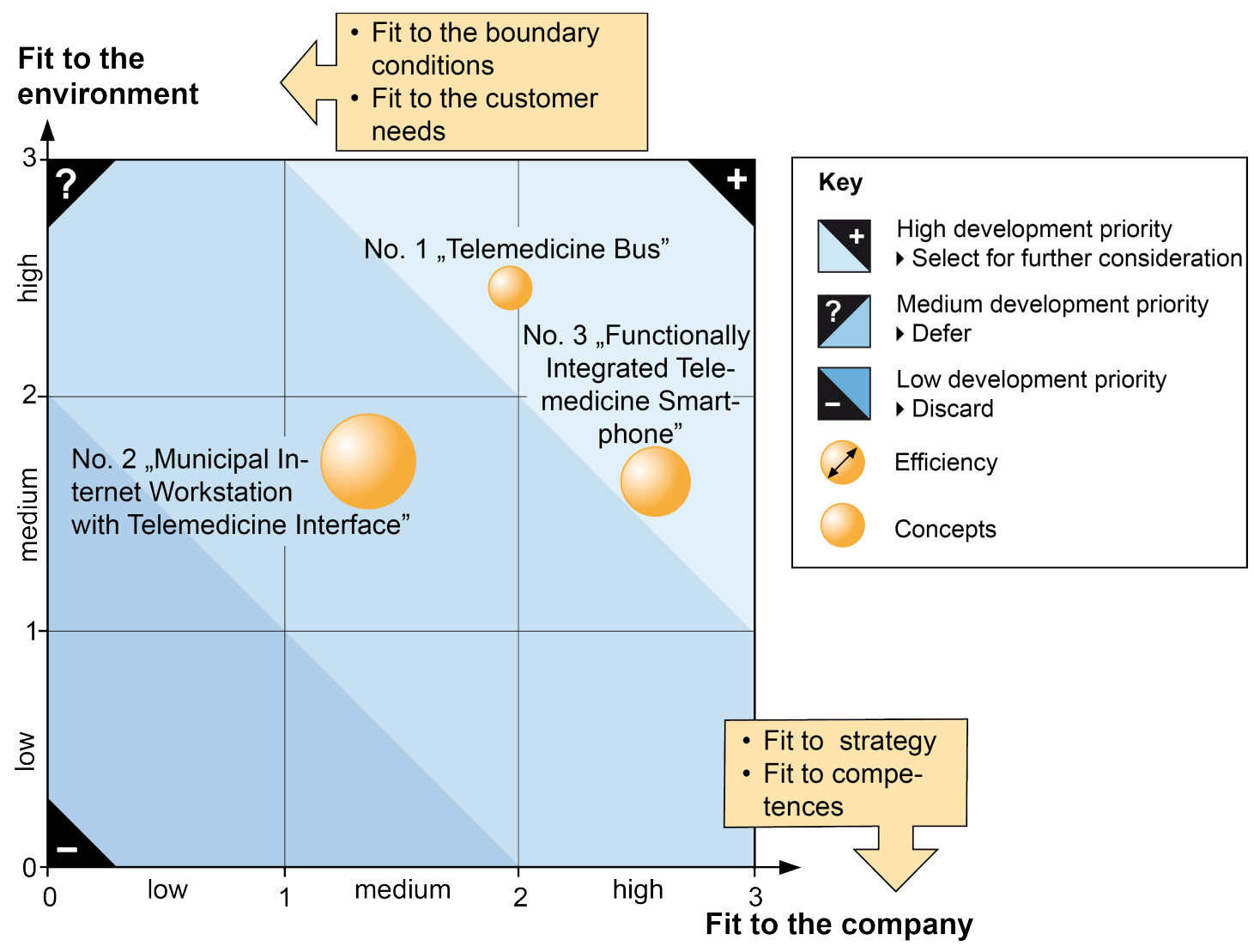

Figure 8. Bubble chart for selecting a promising frugal innovation concept (Lehner, 2016) 


\title{
Approach for a Pattern-Based Development of Frugal Innovations
}

\author{
Anne-Christin Lehner, Christian Koldewey, and Jürgen Gausemeier
}

with the company's competences (fit to the competences).

- Economic efficiency: On the basis of the information available at this time, an initial economic efficiency assessment can be carried out. Its results allow a rough evaluation of the economic efficiency.

The further development priority of a concept increases in the diagonal from bottom left to top right in the bubble chart. Accordingly, ideas should be selected for further development that lie as high as possible in the upper right-hand corner of the chart and are as economical as possible. In the present case, the company selected the concept of the "Telemedicine Bus". The next steps follow the usual procedure for developing market services.

\section{Conclusion}

Markets in developing and emerging countries are becoming increasingly important as the prosperity of the global middle-class increases. However, they demand products that are adapted to the local needs of the population. Frugal innovation offers companies from industrialized countries an excellent opportunity to participate in this development. The method presented gives them a guideline to plan frugal innovations. It is particularly suitable for more complex market services with a high adaptation effort. However, key success factors in the various stages of the value chain must be taken into account (Roland Berger Strategy Consultants, 2013):

- Market analysis: A comprehensive understanding of the customer must be established and, in particular, the willingness of customers to pay. It is just as important to determine what the customer does not want to pay for. In addition, an early analysis of competitor products is of outstanding importance.

- Development: Market-oriented research and development is leading the way in developing market services that address local customer needs. In addition, it is evident that interdisciplinary teams offer a significant advantage here.

- Purchasing and the value chain: Frugal innovations are particularly successful when local suppliers are integrated into the value chain. Flexibility with regard to the existing specifications is also advantageous.
- Marketing and sales: Innovative sales concepts are necessary to reach the targeted customer groups.

Given that the pattern approach is already used in many disciplines, its application to the frugal innovation process seemed very promising. By developing the pattern system, we validated that frugal innovation patterns exist. Furthermore, by introducing and utilizing a pattern-based frugal innovation process, we showed that the pattern approach can be used to develop frugal products and business models. But still, like Hossain and co-authors (2017), we find that there is a lack of conceptual and managerial understanding of frugal innovation. Future research should focus on the enhancement of the pattern system to strengthen the understanding of problems and solutions of frugal innovation. Furthermore, research should focus on frugal innovation strategies. This should comprise the analysis of cannibalization effects, cooperation planning, and brand strategy. For this specific approach, a software tool should be programmed to facilitate the application of the innovation process.

For the practitioners, the article at hand shows an approach to design their own innovation process integrating solution patterns as well as how to generate a frugal innovation pattern system to acquire and store knowledge about frugal innovations. This seems highly promising given that the different problems companies face developing frugal innovations share similarities. That is why we expect a pattern-based search to generate comparable solutions that are both fruitful and frugal. To apply the approach in practice, companies should form an interdisciplinary team of experts from all departments concerned. Their work should be discussed in regular consultations and joint workshops in order to avoid bias. After each phase, management should review the results and decide on the further progress of the project. This ensures that decisions are made transparently and comprehensibly and without bias.

\section{Acknowledgements}

A shorter, German-language version of this article is part of the upcoming book by J. Gausemeier and colleagues: Innovationen für die Märkte von morgen Strategische Planung von Produkten, Dienstleistungen und Geschäftsmodellen (Innovations for the Markets of the Future - Strategic Planning of Products, Services and Business Models). 


\section{Approach for a Pattern-Based Development of Frugal Innovations}

\section{Anne-Christin Lehner, Christian Koldewey, and Jürgen Gausemeier}

\section{About the Authors}

Anne-Christin Lehner (Dr.-Ing.) is employed by Hella GmbH \& Co. KGaA in the field of Operations Strategy \& Capacity Planning. She studied Industrial Engineering with a focus on Electrical Engineering at the University of Paderborn, Germany, and the University of Ottawa, Canada. Until 2016, Anne-Christin was a Research Associate of Professor Gausemeier at the Heinz Nixdorf Institute of the University of Paderborn. Her main focus was on strategic planning and innovation management.

Christian Koldewey (M.Sc.) is a Research Associate at the Heinz Nixdorf Institute of the University of Paderborn, Germany. He works in the team strategic planning and innovation management within the working group strategic product planning and systems engineering at the chair of Professor Gausemeier. His research topics are digital service innovation, business and diversification strategy as well as business model generation. Previously, he studied Mechanical Engineering with a focus on manufacturing technology at the University of Paderborn and the Bielefeld University of Applied Science in Germany.

Jürgen Gausemeier (Prof. Dr.-Ing.) is a Senior Professor at the Heinz Nixdorf Institute of the University of Paderborn, Germany, and is Chairman of the Board of the Leading Edge Cluster "Intelligente Technische Systeme Ostwestfalen-Lippe (it's OWL)", which was initiated by the Federal Ministry of Education and Research. He was speaker of the Collaborative Research Centre 614 "Self-Optimizing Concepts and Structures in Mechanical Engineering" and member of the German Council of Science and Humanities from 2009 until 2015. Jürgen is Initiator and Chairman of the Supervisory Board of the consulting company UNITY AG. Since 2003, he has been a member of "acatech - German Academy of Science and Engineering" and, since 2012, has been its Vice President. In 2014, Jürgen received the Medal of Honor from the academic society "Wissenschaftliche Gesellschaft für Produktentstehung (WiGeP)".

Citation: Lehner, A.-C., Koldewey, C., \& Gausemeier, J. 2018. Approach for a Pattern-Based Development of

Frugal Innovations. Technology Innovation

Management Review, 8(4): 14-27.

http://doi.org/10.22215/timreview/1149

Keywords: frugal innovations, emerging markets, patterns, business model, products and services

\section{References}

Alexander, C., Ishikawa, S., Silverstein, M., Jacobson, M., King, I. F., \& Angel, S. 1995. Eine Muster-Sprache: Städte Gebäude Konstruktion. Vienna: Löckler.

Amshoff, B., Dülme, C., Echterfeld, J., \& Gausemeier, J. 2014. Geschäftsmodellmuster für disruptive Technologien. Berlin: Gausemeier, J.: Vorausschau und Technologieplanung. 10. Symposium für Vorausschau und Technologieplanung, November 20-21, 2014, HNI-Verlagsschriftenreihe, Band 334, Paderborn: $165-190$.

Basu, R. R., Banerjee, P. M., \& Sweeny, E. G. 2013. Frugal Innovation: Core Competencies to Address Global Sustainability. The Journal of Management for Global Sustainability, 1(2): 63-82. http://dx.doi.org/10.13185/JM2013.01204

Bhatti, Y. 2012. What Is Frugal, What Is Innovation? - Towards a Theory of Frugal innovation. Oxford: Said Business School Working Paper Series.

Bhatti, Y., \& Ventresca, M. 2013. How Can 'Frugal Innovation' Be Conceptualized? Oxford: Said Business School Working Paper Series.

Bieger, T., \& Reinhold, S. 2011. Das wertbasierte Geschäftsmodell ein aktualisierter Strukturansatz. In T. Bieger, D. zu KnyphausenAufseß, \& C. Krys (Eds.), Innovative Geschäftsmodelle: Konzeptionelle Grundlagen, Gestaltungsfelder und unternehmerische Praxis: 11-70. Berlin: Springer.

Blessing, L. T. M., \& Chakrabarti, A. 2009. DRM, a Design Research Methodology. London: Springer-Verlag.

Bound, K., \& Thornton, I. 2012. Our Frugal Future - Lessons from India's Innovation System. London: Nesta.

Bower, J. L., \& Christensen, C. M. 1995. Disruptive Technologies Catching the Wave. Harvard Business Review, 72(1): 43-53.

Buschmann, F., Meunier, R., Rohnert, H., Sommerlad, P., \& Stal, M. 2000. Pattern-orientierte Softwarearchitektur: Ein Pattern-System. Bonn: Addison-Wesley.

Capasso, A., Dagnino, G. B., \& Tienari, J. 2013. Resource Constrained Innovation at the Bottom of the Pyramid - Towards a Theoretical Framework. Paper presented at the AIDEA Bicentenary Conference, Bologna, Italy, September 19-21, 2013.

Corfman, R. 1998. An Overview of Patterns. In L. Rising (Ed.), The Patterns Handbook: Techniques, Strategies, and Applications: 19-30. Cambridge: Cambridge University Press.

Eagar, R., van Oene, F., Boulton, C., Roos, D., \& Dekeyser, C. 2011. The Future of Innovation Management - The Next 10 Years. Prism, 1: 21-37.

The Economist. 2010. First Break All the Rules: The Charms of Frugal Innovation. The Economist, April 15, 2010. Accessed April 11, 2018: https://www.economist.com/node/15879359

Ernst, H., Prabhu, J., \& Kahle, H. N. 2013. Base of the Pyramid Innovations - Results of a Research Study. Cambridge: WHU University, Cambridge Judge Business School.

Gausemeier, J., \& Wiendahl, H.-P. 2011. Hebel zur Gestaltung von Produktentstehung, Produktion und Wertschöpfung in Deutschland - Zusammenfassung und Schlussfolgerungen. In J. Gausemeier, \& H.-P. Wiendahl (Eds.), Wertschöpfung und Beschäftigung in Deutschland: 103-108. Berlin: Springer. 


\section{Approach for a Pattern-Based Development of Frugal Innovations}

\section{Anne-Christin Lehner, Christian Koldewey, and Jürgen Gausemeier}

Govindarajan, V., \& Trimble, C. 2012. Reverse Innovation: Create Far From Home, Win Everywhere. Watertown: Harvard Business Review Press.

Heeks, R., Amalia, M., Kintu, R., \& Shah, N. 2013. Inclusive Innovation: Definition, Conceptualisation and Future Research Priorities. Working Paper No. 53. Manchester, UK: Centre for Development Informatics, University of Manchester.

The Heritage Foundation. 2015. Index of Economic Freedom. The Heritage Foundation. Accessed October 12, 2015: http://www.heritage.org/index/ranking

Hilmi, M. F. 2012. Grassroots Innovation from the Bottom of the Pyramid. Current Opinion in Creativity, Innovation and Entrepreneurship, 1(2).

http://dx.doi.org/10.11565/cuocient.vli2.5

Högl, M., \& Weiss, M. 2014. Innovationen in Schwellen- und Entwicklungsländern: Eine Diskussion wichtiger Forschungsfragen. In C. Schultz \& K. Hölzle (Eds.), Motoren der Innovation: Zukunftsperspektiven der Innovationsforschung: 81-96. Wiesbaden: Springer Gabler.

Hossain, M. 2016. Frugal Innovation: A Systematic Literature Review. Available at SSRN:

http://dx.doi.org/10.2139/ssrn.2768254

Hossain, M., Levänen, J., Lindeman, S., \& Wierenga, M. 2017. Frugal Innovation Process: Comparing between Grassroots and Elite Contexts. Paper presented at the 2017 R\&D Management Conference, Leuven, Belgium, July 1-5, 2017.

Hyvärinen, A., Keskinen, M., \& Varis, O. 2016. Potential and Pitfalls of Frugal innovation in the Water Sector: Insights from Tanzania to Global Value Chains. Sustainability, 8(9): 888. https://doi.org/10.3390/su8090888

Kao, H., \& Lee, J. 2010. The Application of Shanzhai Innovation Model in China: The Examples of Mobile Phone, Notebook Computer and Automobile. Paper presented at the Summer Conference on Opening Up Innovation - Strategy, Organization and Technology, Imperial College London Business School, June 16-18, 2010.

Kohl, C., \& Wedekind, J. 2011. Investigations of E-Learning Patterns: Context Factors, Problems, and Solutions. New York: Information Science Reference.

Lehner, A.-C. 2016. Systematik zur lösungsmusterbasierten Entwicklung von Frugal innovations. Paderborn: HNIVerlagsschriftenreihe.

Lehner, A.-C., \& Gausemeier, J. 2015. A Pattern-Based Approach to the Development of Frugal innovations. In Proceedings of the International Society for Professional Innovation Management (ISPIM) Summit, Brisbane, Australia, December 6-9, 2015.

Lehner, A.-C., \& Gausemeier, J. 2016. A Pattern-Based Approach to the Development of Frugal Innovations. Technology Innovation Management Review, 6(3): 13-21.

http://timreview.ca/article/971

Lehner, A.-C., Gausemeier, J., \& Röltgen, D. 2015. Nutzung von Lösungsmustern bei der Entwicklung von Frugal Innovations. In J. Gausemeier (Ed.), Vorausschau und Technologieplanung. 11. Symposium for Foresight and Technology Planning, 347: 11-37. Paderborn: HNI-Verlagsschriftenreihe.

McKinsey Global Institute. 2015. Playing to Win: The New Global Competition for Corporate Profits. New York: McKinsey \& Company.
Mundim, A., Sharma, M., Arora, P., \& McManus, R. 2012. EmergingMarkets Product Development and Innovation: The New Competitive Reality. Chicago, IL: Accenture.

Nijhof, A., Fischer, O., \& Looise, J. K. 2002. Inclusive Innovation: A Research Project on the Inclusion of Social Responsibility. Corporate Social Responsibility and Environmental Management, 9(2): 83-90. https://doi.org/10.1002/csr.10

Prahalad, C. K., \& Mashelkar, R. A. 2010. Innovation's Holy Grail. Harvard Business Review, 88(7/8): 132-141.

Radjou, N., Prabhu, J., \& Ahuja, S. 2012. Jugaad Innovation - Think Frugal, Be Flexible, Generate Breakthrough Growth. San Francisco: Jossey-Bass.

Ray, P., \& Ray, S. 2010. Resource-Constrained Innovation for Emerging Economies: The Case of the Indian Telecommunications Industry. IEEE Transactions on Engineering Management, 57(1): 144-156.

https://doi.org/10.1109/TEM.2009.2033044

Ravallion, M. 2009. The Developing World's Bulging (But Vulnerable) "Middle Class". Washington, DC: The World Bank Development Research Group.

Roland Berger Strategy Consultants. 2013. Frugal Products - Study Results. Munich: Roland Berger Strategy Consultants.

Roland Berger Strategy Consultants. 2015. Simply the Best - Frugal Products Are Not Just for Emerging Markets: How to Profit from Servicing New Customer Needs. Munich: Roland Berger Strategy Consultants.

Seyfang, G., \& Smith, A. 2007. Grassroots Innovations for Sustainable Development: Towards a New Research and Policy Agenda. Environmental Politics, 16(4): 584-603. https://doi.org/10.1080/09644010701419121

Shivaraman, S., Mathur, M., \& Kidambi, R. 2012. Frugal ReEngineering - Innovatively Cutting Product Costs. Chicago: A.T. Kearney.

Tiwari, R., \& Herstatt, C. 2012. Open Global Innovation Networks as Enablers of Frugal innovation: Propositions Based on Evidence from India. Working Paper No. 72. Hamburg, Germany: Hamburg University of Technology.

Tiwari, R., \& Herstatt, C. 2013. Innovieren für preisbewusste Kunden: Analogieeinsatz als Erfolgsfaktor in Schwellenländern. Working Paper No. 75. Hamburg, Germany: Hamburg University of Technology.

Tiwari, R., \& Herstatt, C. 2014. Aiming Big with Small Cars: Emergence of a Lead Market in India. Berlin: Springer.

Universe Foundation. 2013. Frugal Innovation - A Manual. Sondeborg, Denmark: Universe Foundation.

Williamson, P. J. 2010. Cost Innovation: Preparing for a 'Value-forMoney’ Revolution. Long Range Planning, 43(2-3): 343-353. https://doi.org/10.1016/j.lrp.2009.07.008

Zeschky, M., Widenmayer, B., \& Gassmann, O. 2011. Frugal innovation in Emerging Markets. Research Technology Management, 54(4): 38-45. https://doi.org/10.5437/08956308X5404007

Zimmer, W. 1995. Relationships between Design Patterns. In J. Coplien \& D. Schmidt, D. (Eds.), Pattern Languages of Program Design:345-364. Reading, MA: Addison-Wesley. 


\section{Academic Affiliations and Funding Acknowledgements}

Canadà
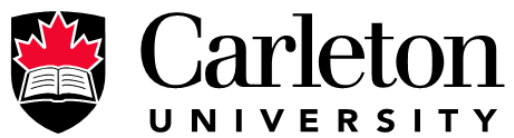

U N I V E R S I T Y

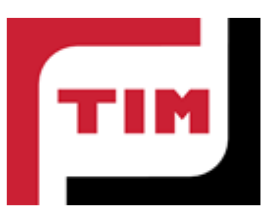

The Federal Economic Development Agency for Southern Ontario (FedDev Ontario; feddevontario.gc.ca) is part of the Innovation, Science and Economic Development portfolio and one of six regional development agencies, each of which helps to address key economic challenges by providing regionallytailored programs, services, knowledge and expertise.

- The TIM Review receives partial funding from FedDev Ontario's Investing in Regional Diversification initiative.

Technology Innovation Management (TIM; timprogram.ca) is an international master's level program at Carleton University in Ottawa, Canada. It leads to a Master of Applied Science (M.A.Sc.) degree, a Master of Engineering (M.Eng.) degree, or a Master of Entrepreneurship (M.Ent.) degree. The objective of this program is to train aspiring entrepreneurs on creating wealth at the early stages of company or opportunity lifecycles.

- The TIM Review is published in association with and receives partial funding from the TIM program. 